\title{
Antitumor properties of salinomycin on cisplatin-resistant human ovarian cancer cells in vitro and in vivo: Involvement of p38 MAPK activation
}

\author{
BEI ZHANG ${ }^{1 *}$, XUEYA WANG $^{2 *}$, FENGFENG CAI $^{1},{\text { WEIJIE } \mathrm{CHEN}^{1}, \mathrm{ULI} \text { LOESCH}^{3} \text { and XIAO YAN ZHONG }}^{1}$ \\ ${ }^{1}$ Laboratory for Gynecologic Oncology, Women's Hospital/Department of Biomedicine, University of Basel; \\ ${ }^{2}$ Nanomedicine Research Group, Medical Intensive Care Unit and ${ }^{3}$ Hospital Pharmacy, \\ University Hospital Basel, CH-4031 Basel, Switzerland
}

Received July 11, 2012; Accepted August 30, 2012

DOI: 10.3892/or.2013.2241

\begin{abstract}
In order to search for alternative agents to overcome chemoresistance during the treatment of ovarian cancer, this study aimed to examine the anticancer effects and action mechanism of salinomycin, a selective inhibitor of cancer stem cells, on cisplatin-resistant human ovarian cancer cell lines in vitro and in vivo. The concentration- $(0.01-200 \mu \mathrm{M})$ and time-dependent (24-72 h) growth inhibitory effects of salinomycin were observed in the ovarian cancer cell lines OV2008, C13, A2780, A2780-cp, SKOV3 and OVCAR3, by measuring cell viability using the resazurin reduction assay. The $\mathrm{IC}_{50}(24 \mathrm{~h})$ range of salinomycin on the six cell lines was found to be 1.7-7.4 $\mu \mathrm{M}$. After cisplatin-resistant $\mathrm{C} 13$ cells were treated with salinomycin, the percentage of apoptotic cells determined by flow cytometry was significantly increased, in a concentration- and time-dependent manner. However, no cell cycle arrest was detected in the G1/G0, S and G2/M phases in the salinomycin-treated and control cells. The Bio-Plex phosphoprotein 5-plex assay (Akt, IкB- $\alpha$, ERK1/2, JNK and p38 MAPK) demonstrated a marked time- and concentration-dependent increase in the phosphorylation of p38 MAPK, subsequent to salinomycin treatment. Moreover, salinomycin significantly suppressed tumor growth in a tumor xenograft model. These findings suggested that salinomycin efficiently inhibits the cisplatin-resistant human ovarian cancer cell line growth through the induction of apoptosis, potentially associated with the p38 MAPK activation.
\end{abstract}

Correspondence to: Professor Xiao Yan Zhong, Laboratory for Gynecologic Oncology, Women's Hospital/Department of Biomedicine, University Hospital of Basel, Hebelstrasse 20, CH-4031 Basel, Switzerland

E-mail: zhongx@uhbs.ch

*Contributed equally

Key words: salinomycin, ovarian cancer, cisplatin-resistant, growth inhibition, apoptosis, p38 MAPK, tumor xenografts

\section{Introduction}

Ovarian cancer remains a leading cause of mortality from gynecological malignancy, with $>204,000$ new cases and 125,000 deaths each year, accounting for $4 \%$ of all cancer cases and $4.2 \%$ of all cancer deaths in women around the world (1). The incidence of ovarian cancer increases with age and $>70 \%$ of the patients are diagnosed with late stage disease after distant metastasis has occurred. The 5-year survival rate for the patients diagnosed with late stage disease is $<20 \%$, even with extensive surgery and chemotherapy $(2,3)$. Chemotherapy with the administration of cisplatin (cisdiamminedichloroplatinum (II)) or cisplatin in combination with taxanes is the current standard of care $(4,5)$. Although the majority of the ovarian tumors were initially sensitive to chemotherapy $(6,7)$, long-term administration of cisplatin has been shown to result in the development of chemotherapeutic drug resistance in the cancer cell population $(8,9)$. Cisplatin resistance is a major obstacle to the successful therapy of recurrent ovarian tumors and responsible for poor long-term overall survival $(6,7)$. The suggested mechanisms for cisplatin resistance include the increase in intracellular thiols in the redox pathway (10), defects in the apoptotic pathway and the altered activation of signaling pathways, such as PI3K/ Akt (11), MAPK (12) or NF- $\mathrm{B}$ (13). Investigators have targeted these pathways in an attempt to circumvent cisplatin resistance $(13,14)$.

Salinomycin is a 751 Da monocarboxylic polyether antibiotic belonging to the group of ionophores that is produced by Streptomyces albus (strain no. 80614) (15). It is commonly used as a coccidiostat in poultry and other livestock and is fed to ruminants to improve nutrient absorption and feed efficiency (16). Recently, salinomycin has been reported to selectively deplete human breast cancer stem cells from tumorspheres and to inhibit mammary tumor growth and metastasis in vivo (17). In another report, salinomycin has been shown to induce apoptosis in human cancer cells, including those showing wild-type p53 or p53 mutation and multi-drug resistance due to the overexpression of $\mathrm{Bcl}-2$, P-glycoprotein or $26 \mathrm{~S}$ proteasomes with deregulated proteolytic activity (18). These results strongly suggested that salinomycin should 
be considered an anticancer compound. The mechanism of the anticancer action of salinomycin has yet to be delineated. Salinomycin has been shown to activate a particular apoptotic pathway not accompanied by cell cycle arrest and independent of tumor suppressor protein p53, caspase activation, the CD95/CD95L system or the proteasome (18). More recently, salinomycin has been reported to overcome $\mathrm{ABC}$ transporter-mediated multidrug and apoptosis resistance (19) and act as a potent inhibitor of multidrug resistance gp170 (20). Furthermore, salinomycin has been shown to inhibit the activity of the Wnt signaling pathway, recently appointed as an essential regulator of cancer stem cell (CSC) properties in chronic lymphocytic leukemia cells (21).

The present study aimed to determine the biological anticancer activity of salinomycin towards the cisplatin-resistant human ovarian cancer cell line and its tumor xenograft model, as well as to derive mechanistic insights into the action of salinomycin. The results showed that salinomycin inhibited cell-growth and induced apoptosis in a cisplatin-resistant human ovarian cancer cell line in vitro and suppressed tumor growth in vivo. The salinomycin-induced apoptosis in the cisplatin-resistant ovarian cancer cell line may correlate with an increase in the activation of p38 MAPK.

\section{Materials and methods}

Cell lines and culture. The ovarian cancer cell lines used in this study were OV2008, C13, A2780, A2780-cp (A/CP), SKOV3 (p53-negative) and OVCAR3 (p53-mutant). Two pairs of cisplatin-sensitive and cisplatin-resistant ovarian cancer cell lines (OV2008 and C13, A2780 and A/CP, respectively) were kindly provided by Dr Gaetano Marverti (University of Modena and Reggio Emilia, Italy). The cell lines were routinely grown in a humidified atmosphere at $5 \% \mathrm{CO}_{2}$ and $37^{\circ} \mathrm{C}$, and then incubated with RPMI-1640 standard medium supplemented with $10 \%$ fetal bovine serum (FBS), antibiotics (100 IU/ml penicillin and $100 \mu \mathrm{g} / \mathrm{ml}$ streptomycin) and L-glutamine $(2 \mathrm{mM})$. Exponentially growing cells were used in the study. These reagents were provided by Invitrogen (Carlsbad, CA, USA).

Growth inhibition assay. The growth inhibitory effects of salinomycin or cisplatin on the six ovarian cancer cell lines were determined by measuring cell viability using the resazurin reduction assay. Briefly, cells were seeded in 100- $\mu 1$ media on 96-well microtitre plates at a density of 5,000 cells/well. Subsequent to overnight incubation, the cells were exposed to a range of different concentrations of salinomycin (S4526; Sigma-Aldrich, St. Louis, MO, USA) or cisplatin (Ebewe $0.5 \mathrm{mg} / \mathrm{ml}$, Ebewe Pharma Schweiz AG, Cham, Switzerland) and grown at $37^{\circ} \mathrm{C}$ under a $5 \% \mathrm{CO}_{2}$ atmosphere for 24-72 $\mathrm{h}$. Resazurin [(5 $\mu \mathrm{l})$ of $0.02 \%$ (w/v)] (Sigma-Aldrich, R7017) in phosphate-buffered saline (PBS) was then added to each well and incubation was continued for an additional $2 \mathrm{~h}$. At the end, fluorescence was read using a Spectramax Gemini XS microplate reader $(\lambda \mathrm{exc}=544 \mathrm{~nm}, \lambda \mathrm{em}=590 \mathrm{~nm})$.

Cell apoptosis detection. Cell apoptosis was detected using the Annexin V-fluorescein isothiocyanate (FITC)/propidium iodide (PI) apoptosis assay kit (BD Pharmingen, San Diego,
CA, USA) in combination with flow cytometry (CyAn ADP; Dako, Carpinteria, CA, USA). Subsequent to pre-treatment with salinomycin for 12,24 and $36 \mathrm{~h}$, as well as solvent control [0.1\% dimethyl sulfoxide (DMSO)], respectively, the cells were collected by quick trypsinization to minimize potentially high Annexin V background levels in adherent cells. The cells were then washed twice with cold PBS and re-suspended in binding buffer at a concentration of $1 \times 10^{6}$ cells $/ \mathrm{ml}$. The cells $(100 \mu \mathrm{l})$ were stained with $5 \mu \mathrm{l}$ Annexin V/FITC and $5 \mu \mathrm{l}$ PI and were incubated in the dark at room temperature for $15 \mathrm{~min}$. Subsequent to the addition of $400 \mu \mathrm{l}$ binding buffer, the cells were analyzed by flow cytometry. Cells negative for both Annexin $\mathrm{V}$ and $\mathrm{PI}$ were viable, Annexin $\mathrm{V}^{+} / \mathrm{PI}^{-}$cells were in early apoptosis, while Annexin $\mathrm{V}^{+} / \mathrm{PI}^{+}$cells were necrotic or in late apoptosis. The percentages of apoptotic cells were analyzed by the FlowJo software (Tree Star, Ashland, OR, USA).

Cell cycle distribution analysis. To evaluate cell cycle profile, cells $\left(\sim 1 \times 10^{6}\right)$, pre-treated with salinomycin for 12 and $24 \mathrm{~h}$ (0.1\% DMSO as the solvent control), were harvested, washed twice with PBS, then fixed and stored in ice-cold $70 \%(\mathrm{v} / \mathrm{v})$ ethanol at $-20^{\circ} \mathrm{C}$. Prior to analysis, the samples were washed again with PBS, and then incubated in PI/RNAse staining buffer (BD Pharmingen) at room temperature in the dark for at least $15 \mathrm{~min}$. Subsequent to filtration with a view to remove cellular debris, the single-cell suspensions were analyzed using a flow cytometer. The cell cycle parameters were analyzed using the FlowJo software.

Phosphoprotein assay. A panel of phosphoproteins was measured in duplicate, using a bead-based multiplex assay (Bio-Plex Phosphoprotein Detection, Bio-Rad Laboratories, Hercules, CA, USA), according to the manufacturer's instructions $(22,23)$. Briefly, the cells were treated with salinomycin or with the solvent control $(0.1 \%$ DMSO) for the indicated time interval and then the cell lysates were collected with the Bio-Plex Cell Lysis kit. The protein concentration was measured with a detergent compatible (DC) protein assay (Bio-Rad Laboratories) and adjusted to $600 \mu \mathrm{g} / \mathrm{ml}$. Coupled beads $(50 \mu \mathrm{l})$, recognizing phosphorylated Akt, IкB- $\alpha$, ERK1/2, JNK and p38 MAPK, respectively, were added to the 96-well filter plate, and were then washed twice. The same volume of the cell lysates was added and incubated with the beads for 15-18 h (overnight). Then, $25 \mu \mathrm{l}$ of biotinlabelled detection antibodies were added after washing and then incubated for $30 \mathrm{~min}$. Streptavidin-PE (50 $\mu \mathrm{l})$ was added subsequent to washing then incubated in the dark for $10 \mathrm{~min}$. After rinsing, $125 \mu \mathrm{l}$ of re-suspension buffer was added, and the phosphoproteins were analyzed by a Bio-Plex 200 system and the Bio-Plex Manager software (Bio-Rad Laboratories). In this assay, the lysates of the phosphotase-treated HeLa cells, TNF- $\alpha$-treated HeLa cells, UV-treated HEK293 cells and EGF-treated HEK293 cells, provided by the Bio-Plex phosphoprotein assay, were used as the background and the positive control of phospho-IкB- $\alpha$ (Ser32/Ser36), phosphop38 MAPK (Thr180/Tyr182), phospho-JNK (Thr183/Tyr185), phospho-Akt (Ser473), as well as phospho-ERK1/2 (Thr202/ Tyr204, Thr185/Tyr187). This experiment was repeated in duplicate. 

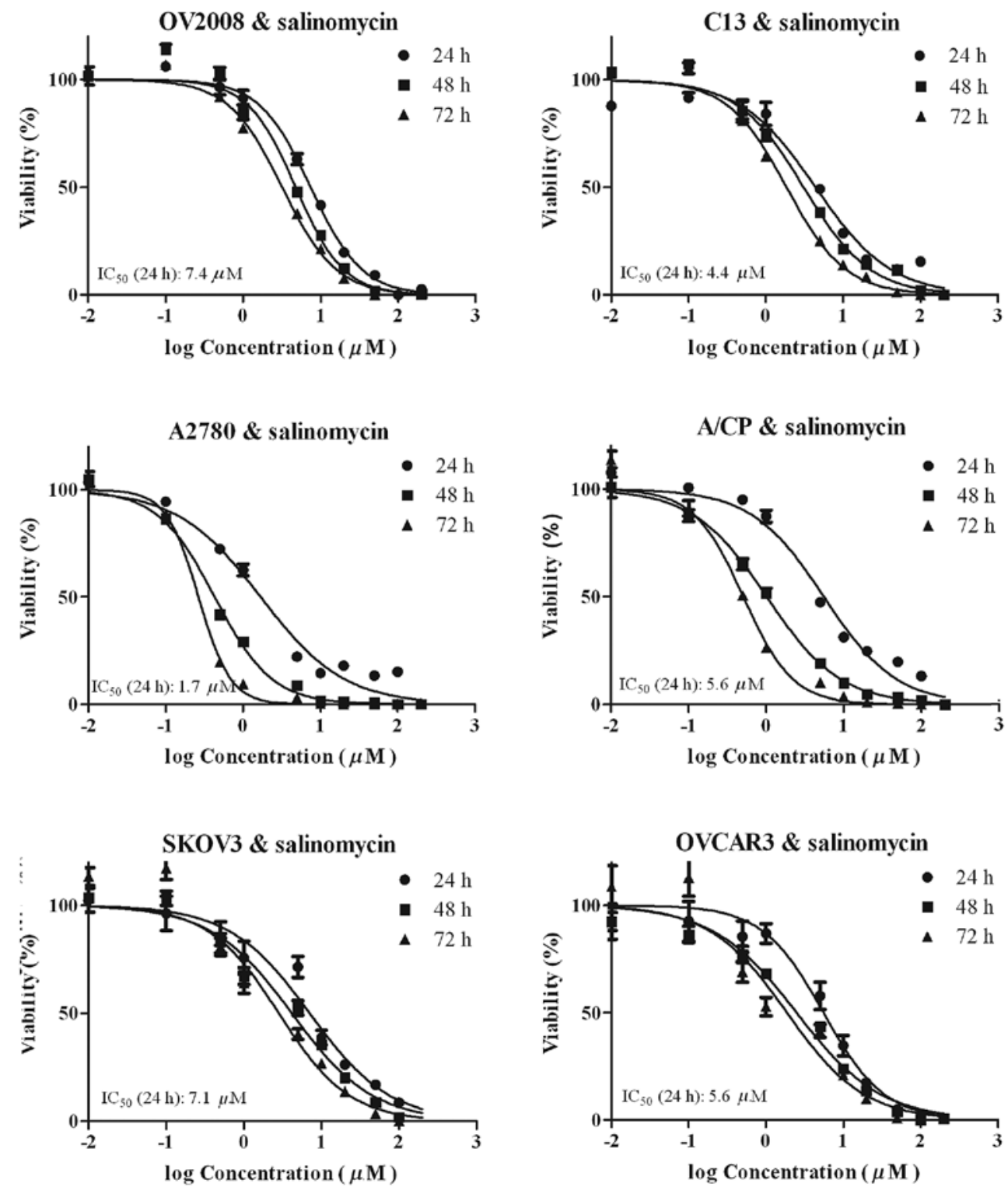

Figure 1. Effect of salinomycin on cell viability in human ovarian cancer cell lines is shown. Cells were exposed to salinomycin at concentrations $(0.01-200 \mu \mathrm{M})$ for 24,48 and $72 \mathrm{~h}$ and cell viability was measured by resazurin reduction assay. Results are expressed as the means \pm SD of quadruplicates from one of three independent experiments.

Ovarian cancer tumor xenografts in mice. Female mice of NOD/SCID were bred in-house in the Animal Center (Tierversuchsstation) of the Department of Biomedicine of the University Hospital of Basel, and were used at 6 weeks of age. The procedures were approved by the Cantonal Veterinary Office (Kantonales Veterinäramt) and performed in accordance with the regulations concerning animal experiments. For the in vivo salinomycin treatment study, cultured ovarian cancer cells $\left(2 \times 10^{6}\right.$ cells/mouse in $0.1 \mathrm{ml}$ saline $)$ were subcutaneously injected into the back of NOD/SCID mice. The following day, mice were randomized into two groups ( $\mathrm{n}=5 /$ group). The treatment was initiated $24 \mathrm{~h}$ subsequent to injection. The two experimental groups were administered salinomycin (5 mg/kg) (17) and 5\% ethanol (vehicle), respectively, through intraperitoneal injection every other day for three weeks. The size of the tumor was measured every two days using a digital vernier caliper. The tumor volume was estimated using the formula: volume $=\left(\mathrm{a} \mathrm{x} \mathrm{b}^{2}\right) \times \pi / 6$, where $\mathrm{a}$ and $b$ are major and minor axes of the tumor.

Statistical analysis. The data were expressed as the mean values \pm standard deviation. The growth-inhibitory curve was analyzed using the GraphPad Prism 5.01 software. The Student's t-test was carried out to compare the groups. $\mathrm{P}<0.05$ was considered to indicate a statistically significant difference.

\section{Results}

Growth-inhibitory effect of salinomycin in ovarian cancer cell lines. The growth-inhibitory effect of salinomycin on OV2008, $\mathrm{C} 13, \mathrm{~A} 2780, \mathrm{~A} / \mathrm{CP}, \mathrm{SKOV} 3$ and OVCAR3 cell lines is shown in Fig. 1. The effect of incubation time and concentration on the viability of the ovarian cancer cell lines by salinomycin was studied. The cells were exposed for 24,48 or $72 \mathrm{~h}$ to salino- 
Table I. $\mathrm{IC}_{50}$ of cisplatin or salinomycin on ovarian cancer cell lines.

\begin{tabular}{|c|c|c|c|c|c|c|}
\hline \multirow[b]{2}{*}{ Cell lines } & \multicolumn{3}{|c|}{ Cisplatin } & \multicolumn{3}{|c|}{ Salinomycin } \\
\hline & $24 \mathrm{~h}$ & $48 \mathrm{~h}$ & $72 \mathrm{~h}$ & $24 \mathrm{~h}$ & $48 \mathrm{~h}$ & $72 \mathrm{~h}$ \\
\hline \multicolumn{7}{|l|}{ OV2008 } \\
\hline $\mathrm{IC}_{50}(\mu \mathrm{M})$ & 8.08 & 2.49 & 0.60 & 7.44 & 4.78 & 3.20 \\
\hline $95 \%$ CI & $6.15-10.63$ & $2.09-2.97$ & $0.52-0.68$ & $6.80-8.14$ & $4.12-5.55$ & $2.90-3.53$ \\
\hline \multicolumn{7}{|l|}{$\mathrm{C} 13$} \\
\hline $\mathrm{IC}_{50}(\mu \mathrm{M})$ & 77.10 & 24.29 & 9.69 & 4.42 & 3.10 & 1.86 \\
\hline $95 \% \mathrm{CI}$ & $65.95-90.13$ & $21.85-27.01$ & $8.19-11.46$ & $3.62-5.39$ & $2.67-3.59$ & $1.67-2.06$ \\
\hline \multicolumn{7}{|l|}{ A 2780} \\
\hline $\mathrm{IC}_{50}(\mu \mathrm{M})$ & 6.48 & 1.60 & 1.03 & 1.70 & 0.43 & 0.27 \\
\hline $95 \% \mathrm{CI}$ & $5.34-7.86$ & $1.30-1.96$ & $0.53-2.00$ & $1.40-2.07$ & $0.39-0.48$ & $0.21-0.33$ \\
\hline \multicolumn{7}{|l|}{$\mathrm{A} / \mathrm{CP}$} \\
\hline $\mathrm{IC}_{50}(\mu \mathrm{M})$ & 26.09 & 3.35 & 1.84 & 5.56 & 1.02 & 0.51 \\
\hline $95 \% \mathrm{CI}$ & $23.53-28.91$ & $2.75-4.09$ & $1.32-2.55$ & $4.75-6.51$ & $0.91-1.13$ & $0.44-0.58$ \\
\hline \multicolumn{7}{|l|}{ SKOV3 } \\
\hline $\mathrm{IC}_{50}(\mu \mathrm{M})$ & 54.55 & 11.39 & 2.09 & 7.08 & 4.17 & 2.83 \\
\hline $95 \% \mathrm{CI}$ & $38.97-76.35$ & $7.17-18.10$ & $1.69-2.59$ & $5.33-9.40$ & $3.47-5.01$ & $2.14-3.76$ \\
\hline \multicolumn{7}{|l|}{ OVCAR3 } \\
\hline $\mathrm{IC}_{50}(\mu \mathrm{M})$ & 13.23 & 2.12 & 0.63 & 5.56 & 2.50 & 1.87 \\
\hline $95 \%$ CI & $10.90-16.06$ & $1.83-2.46$ & $0.55-0.72$ & $4.30-7.18$ & $2.09-2.98$ & $1.32-2.67$ \\
\hline
\end{tabular}

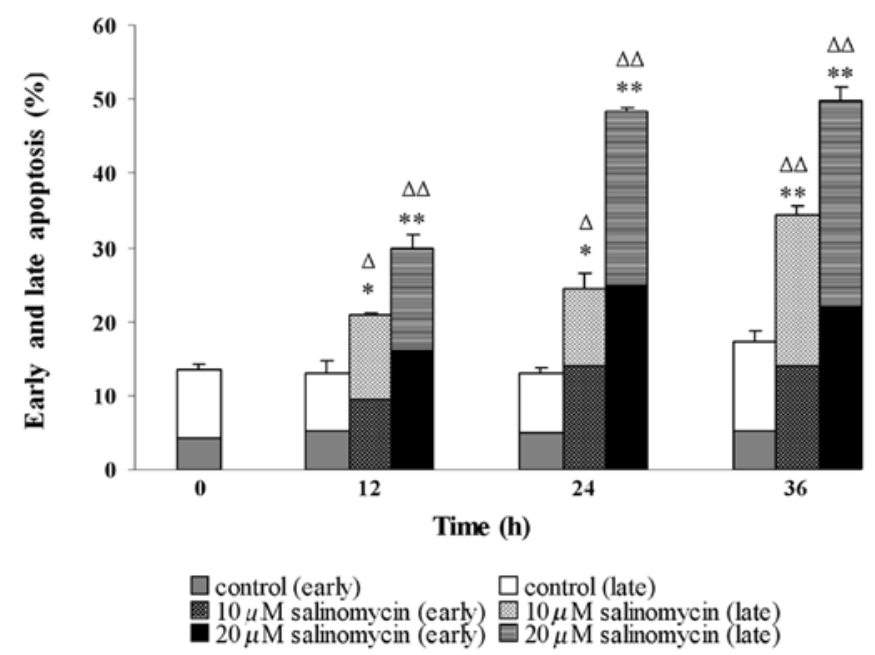

Figure 2. Effect of salinomycin on cell apoptosis in C13 cells is shown. After cells were treated with 10 or $20 \mu \mathrm{M}$ salinomycin as well as solvent control ( $0.1 \%$ DMSO) treatment for 12,24 and $36 \mathrm{~h}$, respectively, the percentage of apoptotic subpopulations was determined by flow cytometry, based on the mean values obtained from three independent experiments. Results are shown as the means \pm SD. Statistically significant differences compared to the control time point $\left({ }^{*} \mathrm{P}<0.05\right.$ and ${ }^{* *} \mathrm{P}<0.01$, respectively). Statistically significant difference compared to the $0 \mathrm{~h}$ control time point $\left({ }^{\Delta} \mathrm{P}<0.05\right.$ and ${ }^{\Delta \Delta} \mathrm{P}<0.01$, respectively).

mycin at a $(0.01-200 \mu \mathrm{M})$ concentration range, and cell viability was measured by the resazurin reduction assay. In the six cell lines studied, the inhibition ratio of cell viability showed a

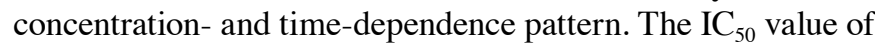

salinomycin or cisplatin on the six ovarian cancer cell lines is shown in Table I. This finding demonstrated that salinomycin was slightly more potent in A2780 compared to the rest of the cell lines and was almost equipotent in the remaining five cell lines, including cisplatin-resistant ovarian cancer cells, such as $\mathrm{C} 13, \mathrm{~A} / \mathrm{CP}$ and SKOV3. The $\mathrm{IC}_{50}(24 \mathrm{~h})$ range of salinomycin on the six ovarian cancer cell lines was 1.7-7.4 $\mu \mathrm{M}$. In addition, salinomycin was more potent in $\mathrm{C} 13$ cells, approximately 9-fold resistant to cisplatin, compared to its parent OV2008 cells (cisplatin-sensitive cells). Thus, the $\mathrm{C} 13$ cisplatin-resistant human epithelial ovarian cancer cell line attracted more attention and was used in most parts of the study.

Effect of salinomycin on tumor cell apoptosis and the cell cycle. Salinomycin-treated C13 cells were analyzed by flow cytometry to distinguish between early or late cell apoptosis, subsequent to simultaneous staining with Annexin V and PI. Compared to the control, salinomycin treatment significantly increased the percentages of apoptotic cells in C13, demonstrating a concentration- and time-dependent pattern (Fig. 2). In the control culture, $4.25 \pm 0.46 \%$ cells were in the early, whereas $9.31 \pm 0.12 \%$ cells were in the late apoptotic stage. Subsequent to treatment of cells with $20 \mu \mathrm{M}$ salinomycin for $12 \mathrm{~h}$, the percentages of apoptotic cells in an early phase increased to $16.2 \pm 0.68 \%$, while that of the late phase increased to $13.7 \pm 1.17 \%$. By contrast, when cells were treated with salinomycin for 24 and $36 \mathrm{~h}, 25.0 \pm 0.70$ and $22.1 \pm 1.91 \%$ of them were in early, and $23.3 \pm 1.08$ and $27.6 \pm 1.13 \%$ in late apoptosis. These results clearly indicated that salinomycin evoked apoptosis in $\mathrm{C} 13$ cells. 

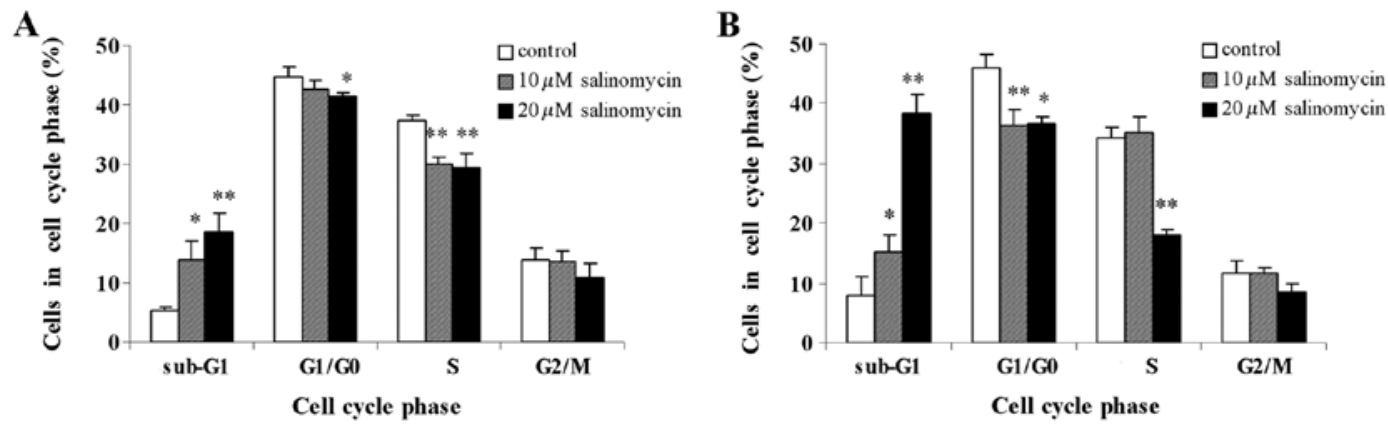

Figure 3. Effect of salinomycin on cell cycle distribution in C13 cells is shown. Cells were treated with 10 or $20 \mu \mathrm{M}$ salinomycin for (A) 12 and (B) $24 \mathrm{~h}$, and with $0.1 \%$ DMSO as the solvent control. The percentages of each cell cycle were evaluated by flow cytometry, based on the mean values obtained from three independent experiments. Results are expressed as the means $\pm \mathrm{SD}$. Statistically significant difference compared to the control $\left({ }^{*} \mathrm{P}<0.05\right.$ and ${ }^{* *} \mathrm{P}<0.01$, respectively).

A
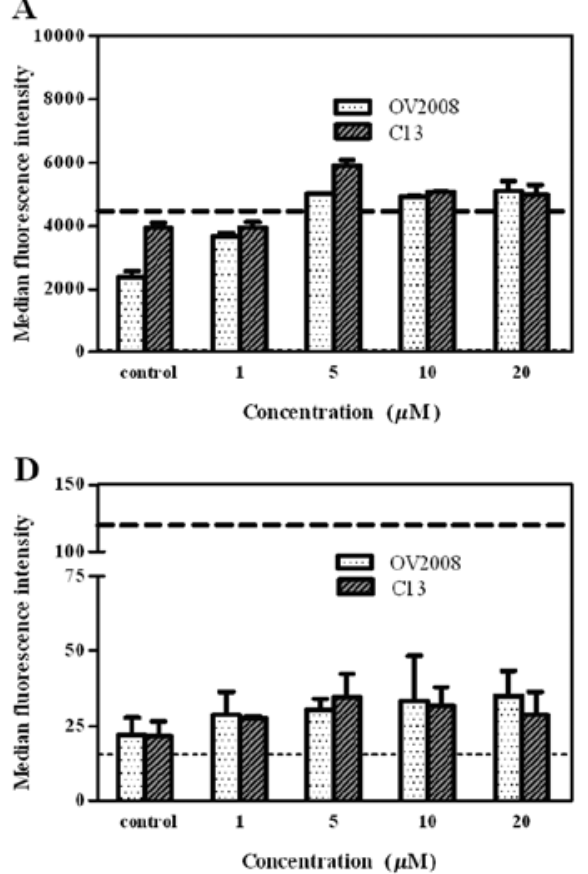

B

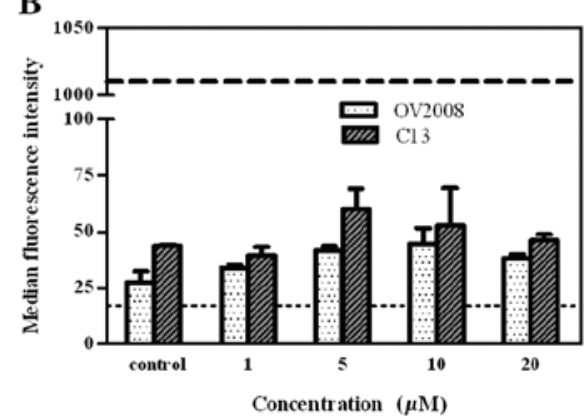

$\mathbf{E}$
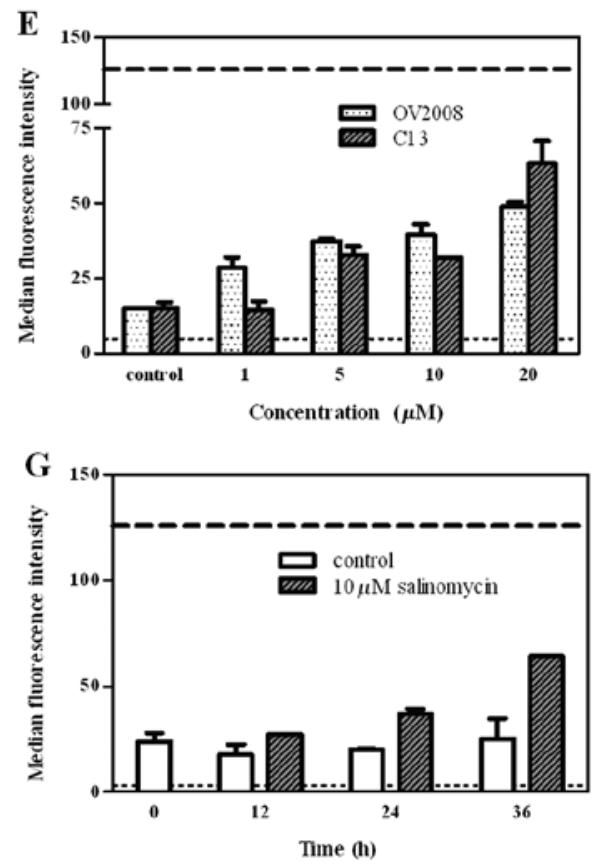

C
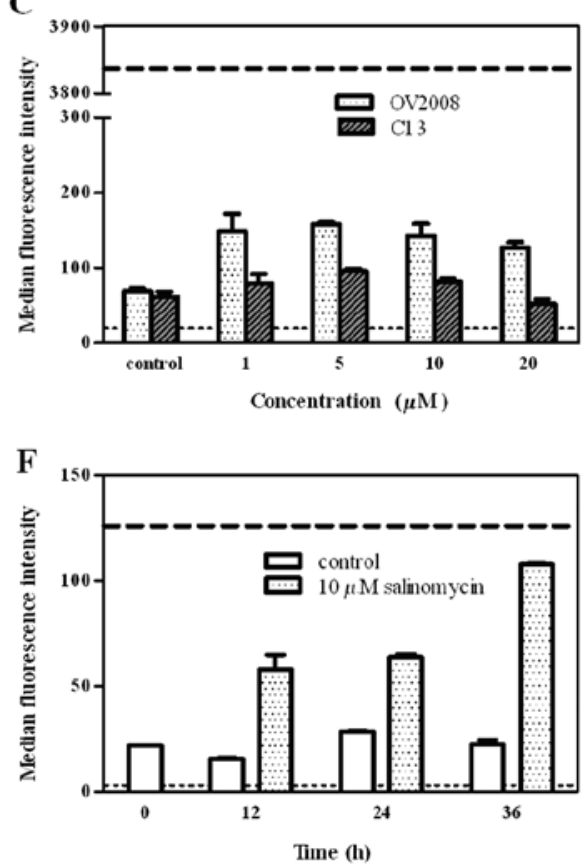

Figure 4. Effect of salinomycin on phosphoproteins levels in OV2008 and C13 cells is shown. The phosphoproteins in OV2008 and C13 cells were assessed by the Bio-Plex assay at $24 \mathrm{~h}$ subsequent to salinomycin treatment at varying doses (1-20 $\mu \mathrm{M}, 0.1 \%$ DMSO as the solvent control). After two washes in ice-cold cell wash buffer, monolayer cells were lysed. The fluorescence intensity of phosphoproteins in cells was counted by the Bio-Plex Suspension Array system: (A) phospho-Akt; (B) phospho-IкB- $\alpha$; (C) phospho-ERK1/2; (D) phospho-JNK and (E) phospho-p38 MAPK. The time-dependent phospho-p38 MAPK levels in (F) OV2008 and (G) C13 were analyzed by the Bio-Plex assay at the indicated intervals, after $10 \mu \mathrm{M}$ salinomycin treatment $(0.1 \%$ DMSO as the solvent control). The dotted line shows the signal intensity of phosphotase-treated HeLa cells as the background control, while the dashed line shows the signal intensity of the positive control. Results are expressed as the means \pm SD.

The effect of different concentrations of salinomycin $(10$ and $20 \mu \mathrm{M})$ on the cell cycle phases was investigated in C13 cells cultured over different times (12 and 24 h) by DNA content analysis, in a flow cytometer. The results showed significantly higher percentages of the cell population in the sub-G1 phase in salinomycin-treated C13 cells in a concentration-dependent manner, whereas the percentages of cells in other phases (G1/G0, S and G2/M phases) were almost 

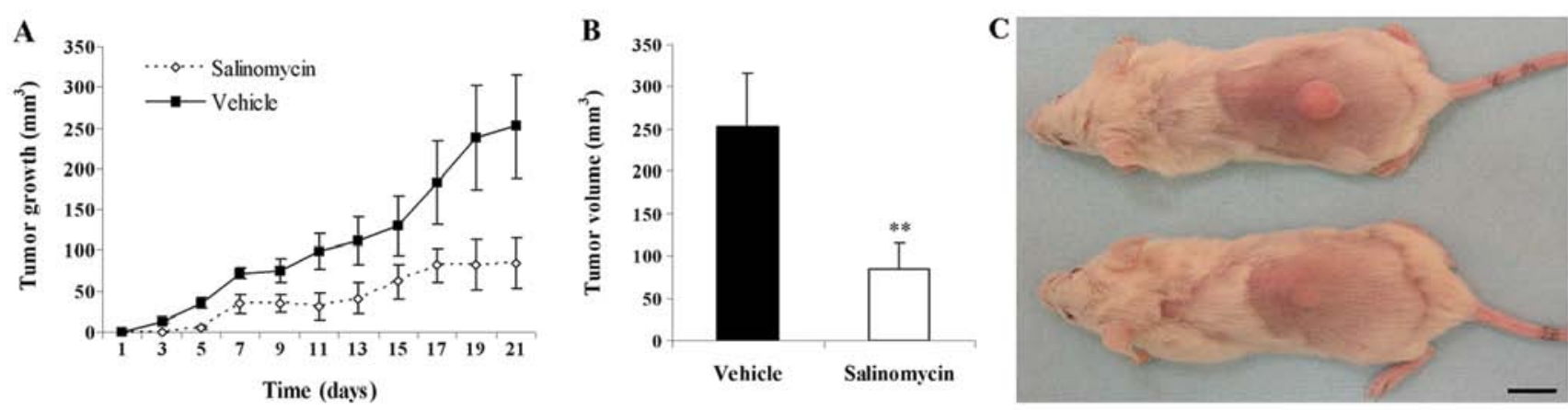

Figure 5. Antitumor activity of salinomycin on NOD/SCID mice bearing human C13 cells is shown. (A) Tumor-growth curves of the mice treated with salinomycin $(5 \mathrm{mg} / \mathrm{kg}$ ) and vehicle control (5\% ethanol). (B) Final volume of tumors in salinomycin- and vehicle-treated animals on day 21 , subsequent to tumor injection. Data are shown as the means \pm SD of tumor volumes $(n=5)$. Statistically significant difference compared to the vehicle control $\left({ }^{* *} \mathrm{P}<0.01\right)$. $(\mathrm{C})$ One of the vehicle control group mice (up) and one of the salinomycin-treated group mice (down). Tumor size in salinomycin-treated mouse (down) was notably reduced compared to the tumor in the vehicle-treated mouse (up). Black bar, $1 \mathrm{~cm}$.

reduced, when compared to the control (Fig. 3). These effects were similar at 12 and $24 \mathrm{~h}$ (Fig. 3). The marked accumulation of cells in sub-G1 phase was another marker for apoptosis, further confirming the results of the Annexin V/PI assay. Additionally, there was no cell cycle arrest in the G1/G0, S and $\mathrm{G} 2 / \mathrm{M}$ phases in salinomycin-treated and control cells, suggesting that salinomycin inhibited the proliferation of $\mathrm{C} 13$ cells not accompanied by cell cycle arrest.

Effect of salinomycin on phosphoproteins levels in OV2008 and $\mathrm{Cl} 3$ cells. To investigate the effect of salinomycin on the phosphoproteins levels in the ovarian cancer cell lines, OV2008 and C13, the regulation of phosphorylation by salinomycin in five proteins was examined using the Bio-Plex phosphoprotein assay. The results showed higher Akt and IкB- $\alpha$ phosphorylation basal levels in untreated $\mathrm{C} 13$ compared to untreated OV2008 cells ( $\sim 1.7$ - and $\sim 1.6$-fold, respectively) (Fig. 4A and B). An increase in the phosphorylation of Akt in response to salinomycin was observed in OV2008 ( 2 2.2-fold) and $\mathrm{C} 13$ cells ( 1.3-fold) (Fig. 4A). ERK was phosphorylated in OV2008 ( 2-fold) and C13 cells ( 1.4-fold) subsequent to the addition of salinomycin, although the level was independent of salinomycin dose and treatment time (Fig. 4C). There was no clear alteration of the phosphorylation of IкB- $\alpha$ (Fig. 4B) and JNK (Fig. 4D) after salinomycin treatment in either type of cell lines. However, a marked concentration-dependent increase was observed in the p38 MAPK phosphorylation in the two cell lines, subsequent to salinomycin exposure for $24 \mathrm{~h}$ (Fig. 4E). p38 MAPK phosphorylation was also enhanced by salinomycin $(10 \mu \mathrm{M})$ after 12,24 and $36 \mathrm{~h}$ of incubation with OV2008 (Fig. 4F) or C13 cells (Fig. 4G), showing a time-dependent pattern. These findings suggested that the salinomycin-induced growth-inhibitory effect and apoptosis in both cell lines is likely to be mediated through the alteration of p38 MAPK phosphorylation.

Evaluation of antitumor activity of salinomycin in vivo. Based on the in vitro results, showing significant cytotoxicity of salinomycin to human ovarian cancer cell lines, the in vivo antitumor efficacy of salinomycin was further evaluated in a cisplatin-resistant human ovarian tumor (C13) xenograft grown in the back of mice. The mice were treated with salinomycin and the change in the tumor volume after the first injection was monitored for 21 days (Fig. 5A). Compared with the vehicle-treated controls, a significant reduction in the tumor volume was observed in the salinomycin-treated mice (Fig. 5C). At the emd of the test, the tumor volume of salinomycin-treated groups and the controls, in the $\mathrm{C} 13$ tumor model, was $84.2 \pm 30.8$ and $252.5 \pm 63.4 \mathrm{~mm}^{3}$, respectively $(\mathrm{P}<0.01$; Fig. 5B).

\section{Discussion}

Recent findings suggest that salinomycin kills human breast cancer stem-like cells (17), induces apoptosis and overcomes multiple mechanisms of resistance to apoptosis in human cancer cells, mainly human haematological tumor cells (18). The aim of the present study was to examine the effects of salinomycin on human ovarian cancer cell lines, including cisplatin-resistant cell lines. As shown in Fig. 1, salinomycin demonstrated a strong growth-inhibitory effect on ovarian cancer cell lines in a concentration- and time-dependent manner. Six ovarian cancer cell lines were selected for this study including cisplatin-resistant cell lines, such as C13, $\mathrm{A} / \mathrm{CP}$ and SKOV3, which are advanced and refractory ovarian cancer cells. Salinomycin proved to be almost equipotent in these cisplatin-resistant cells, exhibiting more growthinhibitory activity towards cisplatin-resistant $\mathrm{C} 13$, compared to cisplatin-sensitive OV2008 cells (Table I). These results are consistent with a previous study on breast cancer cell line, suggesting that drug-resistant cells remain sensitive to salinomycin treatment (17).

Apoptosis (programmed cell death), is an important homeostatic mechanism balancing cell division and cell death, while maintaining the appropriate cell number in the body (24). Therefore, searching for agents that trigger the apoptosis of tumor cells has become an attractive strategy in anticancer medication research (25). In the present investigation, subsequent to salinomycin treatment, flow cytometry results, from both the Annexin V/PI assay (Fig. 2) and sub-G1 populations in cell cycle analysis (Fig. 3), showed a concentration- and time-dependent increase in the percentage of apoptotic $\mathrm{C} 13$ cell 
subpopulations. Consistent with a previous report on various human cancer cells, such as leukemia cells $(18,19)$, these results demonstrated that salinomycin triggered apoptosis in C13 cells .

Cell cycle control is highly involved in the regulation of tumor cell proliferation. Several anticancer and DNA-damaging agents arrest the cell cycle in the G0/G1, S or $\mathrm{G} 2 / \mathrm{M}$ phase and then induce apoptotic cell death $(26,27)$. The results of the present study demonstrated that no cell cycle arrest was observed in the G1/G0, S and G2/M phases in salinomycin-treated $\mathrm{C} 13$ or control cells (Fig. 3), confirming previous findings demonstrating that salinomycin activates a particular apoptotic pathway not accompanied by cell cycle arrest (18).

To better understand the signaling pathways involved in salinomycin-induced growth-inhibitory effects and apoptosis in cisplatin-resistant ovarian cancer cells, the activity of Akt, I $\mathrm{B}-\alpha$, ERK1/2, JNK and p38 MAPK in cisplatin-resistant C13 cells was investigated, compared to cisplatin-sensitive OV2008 cells. To address this issue, multiple phosphoproteins were determined by the Bio-Plex assays with Luminex technology. A recent report showed that the results achieved using Bio-Plex phosphoprotein array analyses significantly correlated $(\mathrm{P}<0.001)$ with those obtained with numerized western blot analyses (23). Furthermore, Bland-Altman analyses clearly demonstrated that Bio-Plex phosphoprotein array may be used instead of western blot analysis providing a unique method of analyzing the multiple phosphoprotein expression in small specimens.

The PI3-kinase/Akt pathway contributed to tumor formation by elevating the activity of the anti-apoptotic action of Akt. Akt inhibited apoptosis through the phosphorylation of Bad, GSK3 and caspase-9, as well as the activation of transcriptional factors, such as Forkhead (FOXO1) and NF- $\kappa \mathrm{B}$ (28). Cisplatin resistance has been reported to be associated with the altered activation of PI3K/Akt signaling pathways in an ovarian cancer cell line (11). The suppression of Akt activation was likely to lead to the activation of pro-apoptotic signaling pathways $(29,30)$. The present study showed that the basal levels of phospho-Akt in untreated cisplatin-resistant C13 cells were higher compared to cisplatin-sensitive OV2008 cells, while salinomycin enhanced the phospho-Akt levels in both $\mathrm{C} 13$ and OV2008 cells (Fig. 4A). However, the growth inhibitory effect of salinomycin on $\mathrm{C} 13$ cells showed no significant difference, compared to OV2008 cells. Moreover, I $\mathrm{B}$ B- $\alpha$ is a downstream Akt substrate. Through the phosphorylation of I $\mathrm{B}$ kinase, Akt activates $N F-\kappa B$, a transcription factor that has been involved in cell survival $(31,32)$. Data indicated that the NF- $\kappa B$ has been linked with cell proliferation, invasion, angiogenesis, metastasis, suppression of apoptosis and chemoresistance in multiple tumors (33). In ovarian cancer cells, the increased phosphorylation of I $\kappa \mathrm{B}-\alpha$ and the constitutive activation of $\mathrm{NF}-\kappa \mathrm{B}$ have been shown to mediate cisplatin resistance, while the inhibition of $N F-\kappa B$ activation sensitizes the ovarian cancer cells to cisplatin (13). In the current study, the basal levels of phospho-IкB- $\alpha$ in untreated cisplatin-resistant $\mathrm{C} 13$ cells were higher compared to untreated cisplatin-sensitive OV2008 cells. However, salinomycin did not induce I $\kappa$ B- $\alpha$ phosphorylation (Fig. 4B). These results indicated that in cisplatin-resistant $\mathrm{C} 13$ cells, salinomycin induces apoptosis through non-Akt/ I $\kappa$ B- $\alpha$-dependent pathways. The exact mechanism of the salinomycin-enhanced phospho-Akt remains unknown and requires additional investigation.

MAPKs are essential components of the signaling transduction mechanism, while being highly involved in cell growth, differentiation and cell apoptosis (34). Recent studies have suggested apoptotic stimuli to be transmitted to caspases through the activation of MAPKs, such as p38 MAPK and JNK (35). Therefore, whether MAPK activation is involved in salinomycin-induced apoptosis in ovarian cancer cell lines (OV2008 and C13) was examined. Data resulting from this study showed that as opposed to JNK or ERK, p38 MAPK is associated with the pro-apoptotic activity of salinomycin (Fig. 4C-G). The p38 MAPK pathway is involved in cancer cell apoptosis and is induced by several chemotherapeutic drugs $(36,37)$. The loss of the capacity to activate p38 MAPK in response to cisplatin treatment was also reported to be a potential mechanism of chemoresistance (38). Marked time- and concentration-dependent increases were detected in the phosphorylation of p38 MAPK subsequent to salinomycin treatment in the two cell lines (Fig. 4E-G). This result suggests that $\mathrm{p} 38$ MAPK activation contributes to the pro-apoptotic effect of salinomycin in ovarian cancer cell lines and that the activation of the p38 MAPK pathway is likely to be involved in the salinomycin-induced apoptosis in ovarian cancer cell lines. However, detailed downstream and upstream signaling molecules of salinomycin-modulated p38 MAPK are unknown and require further investigation.

In the present study, the xenografts of human cisplatin-resistant ovarian cancer (C13) model showed very good efficacy when treated with salinomycin (Fig. 5). Although, the mechanism of cell death in the xenograft tumor model has not yet been ascertained, salinomycin-induced cell apoptosis is likely to account for part of the observed reduction in tumor growth rate and requires further investigation. Additionally, more studies with salinomycin alone in different characterized ovarian cancer cell lines or in combination with other conventional medicatons in vitro and in vivo are still necessary to enhance our understanding of this promising antitumorigenic compound.

In summary, the present study demonstrated that salinomycin inhibits the growth and induces apoptosis in the cisplatin-resistant human ovarian cancer cell line $\mathrm{C} 13$ in vitro and exhibits significant in vivo efficacy in the tumor (C13) xenograft model. The pro-apoptotic effects of salinomycin are not mediated through Akt-dependent pathways, rather possibly associated with p38 MAPK activation. To address the pathway involved additional investigations are required.

\section{Acknowledgements}

The authors would like to thank Dr Gaetano Marverti (University of Modena and Reggio Emilia, Italy) for his kindly supplying cisplatin-resistant ovarian cancer cell lines, Professor Raija Lindberg, Professor Christoph Rochlitz, Dr Serdar Korur, Dr LiFen Xu, Dr Bin Fan, Dr HaiFeng Ye, Mr. Jan Voelzmann, Mr. Lei Fang, Ms. Zeinab Barekati, Mrs. Corina Kohler, Mr. Ramin Radpour, Mrs. HongBo Chen and Mrs. Vivian Kiefer for their kind help. This study was partly financed by the Swiss National Science Foundation (320030_124958/1) Basel, Switzerland and Dr Hans Altschueler Stiftung. 


\section{References}

1. Parkin DM, Bray F, Ferlay J and Pisani P: Global cancer statistics, 2002. CA Cancer J Clin 55: 74-108, 2005.

2. Morrison $\mathrm{J}$ : Advances in the understanding and treatment of ovarian cancer. J Br Menopause Soc 11: 66-71, 2005.

3. Munkarah A, Chatterjee M and Tainsky MA: Update on ovarian cancer screening. Curr Opin Obstet Gynecol 19: 22-26, 2007.

4. McGuire WP III and Markman M: Primary ovarian cancer chemotherapy: current standards of care. Br J Cancer 89 (Suppl): S3-S8, 2003.

5. Bristow RE and Chi DS: Platinum-based neoadjuvant chemotherapy and interval surgical cytoreduction for advanced ovarian cancer: a meta-analysis. Gynecol Oncol 103: 1070-1076, 2006.

6. Cannistra SA: Cancer of the ovary. N Engl J Med 351: 2519-2529, 2004.

7. Kelland LR: Emerging drugs for ovarian cancer. Expert Opin Emerg Drugs 10: 413-424, 2005.

8. Harries $\mathrm{M}$ and Gore M: Part II: chemotherapy for epithelial ovarian cancer-treatment of recurrent disease. Lancet Oncol 3: 537-545, 2002.

9. Harries $\mathbf{M}$ and Gore $\mathrm{M}$ : Part I: chemotherapy for epithelial ovarian cancer-treatment at first diagnosis. Lancet Oncol 3: 529-536, 2002.

10. Jansen BA, Brouwer J and Reedijk J: Glutathione induces cellular resistance against cationic dinuclear platinum anticancer drugs. J Inorg Biochem 89: 197-202, 2002.

11. Lee S, Choi EJ, Jin C and Kim DH: Activation of PI3K/Akt pathway by PTEN reduction and PIK3CA mRNA amplification contributes to cisplatin resistance in an ovarian cancer cell line. Gynecol Oncol 97: 26-34, 2005.

12. Choi KC, Auersperg N and Leung PC: Mitogen-activated protein kinases in normal and (pre)neoplastic ovarian surface epithelium. Reprod Biol Endocrinol 1: 71, 2003.

13. Mabuchi S, Ohmichi M, Nishio Y, et al: Inhibition of NFkappaB increases the efficacy of cisplatin in in vitro and in vivo ovarian cancer models. J Biol Chem 279: 23477-23485, 2004.

14. Rudin CM, Yang Z, Schumaker LM, et al: Inhibition of glutathione synthesis reverses $\mathrm{Bcl}-2$-mediated cisplatin resistance. Cancer Res 63: 312-318, 2003.

15. Miyazaki Y, Shibuya M, Sugawara H, Kawaguchi O and Hirsoe C: Salinomycin, a new polyether antibiotic. J Antibiot 27: 814-821, 1974.

16. Callaway TR, Edrington TS, Rychlik JL, et al: Ionophores: their use as ruminant growth promotants and impact on food safety. Curr Issues Intest Microbiol 4: 43-51, 2003.

17. Gupta PB, Onder TT, Jiang G, et al: Identification of selective inhibitors of cancer stem cells by high-throughput screening. Cell 138: 645-659, 2009.

18. Fuchs D, Heinold A, Opelz G, Daniel V and Naujokat C: Salinomycin induces apoptosis and overcomes apoptosis resistance in human cancer cells. Biochem Biophys Res Commun 390: 743-749, 2009.

19. Fuchs D, Daniel V, Sadeghi M, Opelz G and Naujokat C: Salinomycin overcomes ABC transporter-mediated multidrug and apoptosis resistance in human leukemia stem cell-like KG-1a cells. Biochem Biophys Res Commun 394: 1098-1104, 2010.
20. Riccioni R, Dupuis ML, Bernabei M, et al: The cancer stem cell selective inhibitor salinomycin is a P-glycoprotein inhibitor. Blood Cells Mol Dis 45: 86-92, 2010.

21. Lu D, Choi MY, Yu J, Castro JE, Kipps TJ and Carson DA: Salinomycin inhibits Wnt signaling and selectively induces apoptosis in chronic lymphocytic leukemia cells. Proc Natl Acad Sci USA 108: 13253-13257, 2011.

22. Chang L and Karin M: Mammalian MAP kinase signalling cascades. Nature 410: 37-40, 2001.

23. Chergui F, Chretien AS, Bouali S, et al: Validation of a phosphoprotein array assay for characterization of human tyrosine kinase receptor downstream signaling in breast cancer. Clin Chem 55: 1327-1336, 2009

24. Martin SJ and Green DR: Apoptosis and cancer: the failure of controls on cell death and cell survival. Crit Rev Oncol Hematol 18: 137-153, 1995.

25. Reed JC: Apoptosis-targeted therapies for cancer. Cancer Cell 3: 17-22, 2003.

26. Schwartz GK and Shah MA: Targeting the cell cycle: a new approach to cancer therapy. J Clin Oncol 23: 9408-9421, 2005.

27. Vermeulen K, Van Bockstaele DR and Berneman ZN: The cell cycle: a review of regulation, deregulation and therapeutic targets in cancer. Cell Prolif 36: 131-149, 2003.

28. Katso R, Okkenhaug K, Ahmadi K, White S, Timms J and Waterfield MD: Cellular function of phosphoinositide 3-kinases: implications for development, homeostasis, and cancer. Annu Rev Cell Dev Biol 17: 615-675, 2001.

29. Fraser M, Leung BM, Yan X, Dan HC, Cheng JQ and Tsang BK: p53 is a determinant of X-linked inhibitor of apoptosis protein/Akt-mediated chemoresistance in human ovarian cancer cells. Cancer Res 63: 7081-7088, 2003.

30. Weir NM, Selvendiran K, Kutala VK, et al: Curcumin induces $\mathrm{G} 2 / \mathrm{M}$ arrest and apoptosis in cisplatin-resistant human ovarian cancer cells by modulating Akt and p38 MAPK. Cancer Biol Ther 6: 178-184, 2007.

31. Medema RH, Kops GJ, Bos JL and Burgering BM: AFX-like Forkhead transcription factors mediate cell-cycle regulation by Ras and PKB through p27kip1. Nature 404: 782-787, 2000.

32. Hayden MS and Ghosh S: Shared principles in NF-kappaB signaling. Cell 132: 344-362, 2008.

33. Aggarwal BB: Nuclear factor-kappaB: the enemy within. Cancer Cell 6: 203-208, 2004.

34. Ono $\mathrm{K}$ and Han J: The p38 signal transduction pathway: activation and function. Cell Signal 12: 1-13, 2000.

35. Park SJ and Kim IS: The role of p38 MAPK activation in auranofin-induced apoptosis of human promyelocytic leukaemia HL-60 cells. Br J Pharmacol 146: 506-513, 2005.

36. Wagner EF and Nebreda AR: Signal integration by JNK and p38 MAPK pathways in cancer development. Nat Rev Cancer 9: 537-549, 2009.

37. Bulavin DV and Fornace AJ Jr: p38 MAP kinase's emerging role as a tumor suppressor. Adv Cancer Res 92: 95-118, 2004.

38. Brozovic A, Fritz G, Christmann M, et al: Long-term activation of SAPK/JNK, p38 kinase and fas-L expression by cisplatin is attenuated in human carcinoma cells that acquired drug resistance. Int J Cancer 112: 974-985, 2004. 